\title{
13
}

\section{Innovative Procurement for Health and Industrial Development}

Joanna Chataway, Geoffrey Banda, Gavin Cochrane

and Catriona Manville

\section{Introduction}

Procurement is then an integral part of health policy. However, it is of course also a part of industrial policy. This is because the way in which purchasing decisions are structured and regulated impact profoundly on the way in which production happens. Thus, consideration of the pros and cons associated with procurement regimes needs to be in terms, not only of whether immediate health policy priorities are achieved, but also in light of longer term sustainability of supply of innovative health products. Thus, price, value and innovation are closely interwoven. (Srinivas, 2012: 126)

Part II of this book has demonstrated that building synergies between health systems and industrial development is a complex process of reshaping the politics and political economy of the two systems. A key tool for building and sustaining health-industry relationships, as Smita Srinivas observes above and as some Part I chapters also emphasized, is procurement. Yet procurement remains under-researched and over-simplified as a technical, linear, ordering and delivery process (see Chapter 8), rather than an exercise in deepening and strengthening the domestic economy through market and non-market relationships building.

This chapter aims to shift the literature on health sector procurement into a more developmental mould. It is an innovative procurement chapter in the conceptual sense, addressing the question of how health sector procurement can be developmental both by addressing health sector needs and values and by sustaining industrial suppliers. It also puts forward innovative arguments, exploring in some detail how 
procurement can constitute a business asset, and using the example of value-based pricing (VBP) in medicines procurement to explore how procurement can better address health sector needs in marketized and fragmented lower-income health systems.

The chapter is divided into two sections. The first section focuses on procurement as an industrial policy in African pharmaceutical markets. It takes a detailed microeconomic look at procurement design from the perspective of local pharmaceutical firms, for whom access to working capital is a major developmental constraint. Using illustrative data from Zimbabwe, the chapter shows that procurement can be either a source of finance or a serious drain on the finances of firms that operate in the context of high bank charges and interest rates, and in highly competitive markets. Careful procurement redesign can have a substantial impact on firms' cash flow and investment prospects.

The second section turns to innovative procurement strategies that stitch industrial production and innovation into the values and needs of health sector users in African countries. It explains and examines the emergent practice of value-based pricing (VBP) as a tool to link medicines prices to health needs. So far applied mainly in high-income countries, VBP nevertheless falls within a category of global and local procurement initiatives that try to foreground need in the design of public procurement. The discussion recognizes that public procurement, because of its scale and the values it embodies, is not simply a process of market purchase. Medicines markets and other related institutions are co-created by public and private sectors in complex and diverse ways. Integral to this pattern of interaction and articulation is the way in which medicines are purchased and the way in which prices are determined. These decisions are political as well as economic, as reflected in the Srinivas quote above.

\section{Public procurement as an industrial policy tool}

In the economic development literature, and in the debates on public policies such as defence procurement, there is a long-standing recognition that public procurement can operate as industrial policy. 'Buy local' campaigns and local preferences often formed part of import substitution policies of the type discussed in Part I. The liberalization policies of the 1980s, in both lower-income and higher-income countries, generally removed local procurement preferences and employed international competitive tendering to open up domestic markets to external competition. The development economist Sanjaya Lall, whose 
conceptual framework of industrial capabilities is used throughout this book, was a persistent proponent of the continuing need for industrial development policy in these 'globalized' and fast-moving market contexts. In the early 2000s he posed the question: 'What can poor countries do to strengthen their industrial competitiveness in the international economic setting?' (Lall 2003). His argument that in developing countries, industrial capabilities (technological, financial, organizational and dynamic) develop slowly, and are cumulative and 'path dependent' as industries and institutions build on existing skills (Chapter 2), implied the need for local policy interventions such as local content rules for firms' procurement. Lall (2003) identified firms' procurement capabilities, as well as those of governments, as elements of cumulative industrial improvement, and recognized the importance of developing larger groups of firms in one sector so that they generate 'spill-over' benefits (Chapter 2).

Much writing on procurement focuses on its role in providing a market for locally supplied goods and services, and hence sustaining business development (Ogot et al., 2009; Uyarra and Flanagan, 2009; see also Chapter 3). The market impact of public procurement is very large. Among OECD (high-income) countries in 2011, 13\% of GDP on average was spent by government on procurement of goods and services (OECD nd). In some African countries, outsourcing has rapidly increased the size of public procurement. In Kenya for example, public procurement as a percentage of GDP rose from about $6 \%$ in 2002 to $27 \%$ in 2008 (Ogot et al., 2009).

Lall's framework indicates, however, that public procurement as a developmental tool should go beyond providing a market, to support local industrial innovation. Public health procurement can act as a financing and incentive mechanism to improve technological capabilities, a key element of pharmaceutical industry development as discussed throughout this book. Increasingly, public procurement is promoted as an industrial and innovation policy tool (Kattel and Lember, 2010; Uyarra and Flanagan, 2009). Public procurement creates and enhances markets for new and existing technologies by shaping the demand environment. It can promote sustainable consumption and production patterns: for example, the US government in 1993 issued an Executive Order for all federal agencies to procure energy-efficient computers, resulting in market transformation for Energy Star computer equipment (Kjöllerström, 2008). Procurement can target purchase of goods and services that are new to the country, or new to the world. This chapter explores innovative ways to strengthen the role of procurement in 
relation to pharmaceutical industry development and the needs of the health sector in Sub-Saharan African countries.

\section{Trade credit and working capital: the view from the firms}

To understand how the financial aspects of procurement design can influence industrial development, it helps to start by analysing how pharmaceutical firms in Africa can use trade credit to reduce borrowing and keep down manufacturing costs. Firms can use their input suppliers as an in-kind financing mechanism, via trade credit, in order to reduce their call on their own funds or expensive bank finance. Firms' private sector procurement mechanisms therefore play a critical role in managing working capital financing requirements and cash flows.

By negotiating for generous trade credit terms, firms can fund varying proportions of raw material procurement, production and logistics processes, and sometimes influence the debtors' collection period. Astute use of these options turns the firms' own procurement process into a generator of in-kind finance. Failure to use them causes the firm to haemorrhage cash if it pays suppliers in advance or opts not to stretch its suppliers by paying their invoices early, before reaching the limit of their credit terms.

We describe here how trade credit can aid small to medium enterprises in accessing in-kind finance through contractual relationships with larger and more established firms and organizations with better access to finance. Suppliers endowed with market power and reputation can access formal credit (usually cheaply) from banks and then extend trade credit (an in-kind loan) to buyers with less access to bank or own finance (Nilsen, 2002; Petersen and Rajan, 1997). Because suppliers choose to whom to advance trade credit, trade credit serves as a screening and monitoring device for suppliers (Berlin, 2003). The fact that there are more suppliers, who are better at evaluating credit risk, than there are financial intermediaries makes trade credit an important source of finance in an economy. When suppliers extend credit to buyers, they reduce transactional costs, making business transactions cheaper and easier (Gianetti et al., 2011).

Trade credit is therefore a cheap source of short-term, external, in-kind finance, advanced not as money but goods on credit. If firms understand how to handle finance (if they have good finance capabilities, see Chapter 15), they can use trade credit to reduce cautionary cash holdings thereby alleviating cash flow problems. 
Thus for firms in poorly developed markets, trade credit assumes great importance: there is evidence that industries have an elevated dependence on trade credit in countries with poorly developed financial markets (Fisman and Love, 2003). For Zimbabwe, Fafchamps (1997), using evidence from the 1993 Regional Program for Enterprise Development (RPED) panel survey of 200 Zimbabwean companies, found that trade credit indeed played a significant role in financing enterprises. Trade credit as a percentage of outstanding balances constituted $27 \%$ for micro enterprises, $26 \%$ for small enterprises, $30 \%$ for medium enterprises and $30 \%$ for large enterprises.

However the economic deterioration of the 2000s decade in Zimbabwe caused a high level of uncertainty, shortage of foreign currency and increased country risk. Consequently, local firms found it difficult to access trade credit from suppliers for APIs and excipients. The dearth of trade credit and reliance on expensive bank finance throttled financial breathing space for the companies.

In those circumstances, firms can find themselves in a perverse situation, whereby local pharmaceutical firms are funding suppliers instead of vice versa. Local companies had low bargaining power because they purchased small quantities of raw materials, and their suppliers were not worried if they lost them as customers. Local firms procured raw materials from merchants and brokers with critical mass to move 15 to 30 tonnes of products, and the brokers then sold smaller quantities at higher margins to local firms. APIs and excipients were paid for in advance because suppliers feared country political risk and foreign currency risk, a legacy from the times when Zimbabwe had serious foreign currency shortages despite the country's subsequent shift to using a basket of foreign currencies. Zimbabwean firms, because they paid in advance, were therefore financing economically stronger suppliers in India and China.

Where international suppliers sold to local firms, they also reduced their perceived risk by demanding a letter of credit (LC). The LC costs $2.5 \%$ of value, plus charges for establishing the LC and transaction charges. Local firms sought to reduce these high financing costs by negotiating for in-country bonded warehouses to hold goods for purchase, reducing delays due to shipping and customs clearance and hence the period when the firm would be out of pocket while awaiting the raw materials. Broadly, the trade financing pattern became another example of a perverse subsidy from weaker African economies to stronger trade partners, which one can find reflected also in other markets. 


\section{Public procurement terms as a financial asset for businesses}

The discussion above demonstrates just how strongly a pattern of trade financing can influence the cash flow and business development of local firms. It follows that the design of the payment and credit systems used in public sector procurement can strongly affect the businesses from which the government purchases goods and services. The payment mechanisms in public procurement constitute implicit business financing mechanisms - or a drain on the business.

Public drug procurement payments can be made in at least in three ways; advance payment, cash on delivery or credit terms. Each of these payment modes affects the manufacturers' cash flows, cost of finance and eventually the cost of manufacturing pharmaceuticals. The payment terms can be a source of finance for the firm to use in the production process, or they can cause the producer to seek external expensive finance whilst awaiting payment for goods produced and delivered for periods ranging up to six months.

Advance payment provides direct business funding, as payment is made in advance of goods and services delivery. Advance payment reduces the need for manufacturing firms to borrow expensive bank finance when it does not have sufficient cash holdings. With advance payment, the firm uses these funds to purchase raw material, fund the production process and pay labour. While advance payment, in accounting terms, becomes a short-term liability on the balance sheet of the firm, nevertheless the funds obtained for the pharmaceutical products to be supplied constitute an asset (cash holding) that the firm uses for production and logistics.

With the cash-on-delivery payment method, the buyer pays on receipt of goods and services. The manufacturing firm therefore funds raw material acquisition, production and logistics with either own or borrowed (expensive) funds. Compared to the advance payment method, cash on delivery therefore imposes varying degrees of financing costs on the firm. If the firm uses its own funds, the financing costs are lower than bank borrowing, though accountants will argue that using internally generated funds has important opportunity costs for the business.

The third payment method involves credit terms. The manufacturing firm delivers goods to the procurement agency, which pays after a certain pre-agreed period of time from the date they receive the invoice. The period can generally range from 30 to 90 days and in some instances as much as 180 days. This is the most strenuous payment method of the three described for the manufacturing firm's cash flows. The firm must fund raw materials acquisition, production and logistics processes 
through the period up to payment. The firm must also have skills in chasing on-time payment by the buyer. This chasing process is especially difficult in many instances when the government or state agencies are the buyer, and they need to wait for disbursement of funds from central treasury (see, e.g. Chapter 3). Onerous credit terms of this kind have constrained many African pharmaceutical manufacturing firms to resort to very expensive bank financing prior to receiving payment.

In effect, many local pharmaceutical firms have no option but to provide the government with credit terms: they are effectively helping to finance the local health system. This generates recurrent cash flow problems as they try to fund successive operating cycles. The process of waiting for payment, especially on an order which is large relative to the firm's capacity, can undermine the firm's ability to procure raw materials and pay labour and associated production costs for the next production cycle, as well as constraining effective sales and distribution.

In these constrained situations, there are ways in which a confirmed order or an invoice can be used by a firm to fund production cycles. Two possibilities are a supply chain structured-credit finance approach, and invoice discounting or factoring.

In the first, supply chain structured-credit approach, the firm can use the strength of the procurement agency's own high credit standing. Once the firm has a confirmed order, it can go to a bank to approve a credit facility with conditions. One of the conditions could be the firm assigns the amount payable after fulfilment of the order to the bank. By assigning the firm's (creditworthy) debtors to the bank, it gives the bank control over the funds to be paid. Because funds are disbursed before products have been produced, the firm needs to procure raw material and produce and deliver products before the buyer pays. Consequently, this type of financing carries production, performance and payment risk, hence the need for the firm to have an acceptable production reputation and for the buyer to have good payment reputation. What is key is that the firm can access funds based on a confirmed order from a reputable buyer: an efficient public procurement body that pays reliably can fulfil this role.

The second approach of invoice discounting and factoring requires a much broader and deeper financial institution architecture in the country, including banks and factoring and discounting institutions. This financing method involves a financial institution paying a proportion (up to $85 \%$ ) of invoice value to a firm in advance, against invoices billed to the firm's buyers. Factoring and invoice discounting are prepayment methods against a sales ledger for a firm - in other words, it offers advance or early payment to the firm that sold its goods. Instead of the 
firm waiting for payment by the buyer after, say, 180 days, the firm is able to access working capital finance to fund its production cycles. In this instance, instead of getting advance payment from the customer, the firm gets the advance payment (a proportion) from the financial institution.

Essentially invoice discounting and factoring work in the same way, the difference residing in who has credit control over collection of the debt (amount payable to the supplier). With discounting, the firm has control on debt collection, while in factoring, the firm hands over the collection of the debt to the financial institution, writing formally to its customers to pay the bank directly; the bank then carries the responsibility of collecting the debt.

It follows that if the public procurement agency for the health sector has a good track record for paying on time, it opens up an avenue for firms to access funds based on invoices. This financing approach is attractive because production risk is no longer an issue as the products have already been manufactured. The greatest risk is payment risk by the procurement agency, since many agencies procuring medicines using African government funds may find it hard to pay consistently on time, since their own funding may be erratic (see Chapter 8).

\section{Procurement as an asset: a Zimbabwean example}

Where there is political will and substantial financing, public - including donor-backed -procurement can become a substantial asset for local manufacturing firms and the health systems they supply. An example is the support generated for manufacturing anti-retroviral (ARV) drugs in Zimbabwe. The Zimbabwean government initially created and assured the market for locally produced ARVs by providing a funding mechanism, in a context where there were strong local manufacturing capabilities. As a result, Zimbabwe became one of the first African countries to manufacture ARVs locally, in 2003. We explore how this came to pass.

During the economic challenges of the late 1980s and 1990s, Zimbabwe faced a huge social and health challenge emanating from the HIV/AIDS pandemic. HIV/AIDS was placing a huge strain on an overburdened and underfunded health system. In response, the government converted an existing drought levy into the AIDS levy to finance the HIV/AIDS programme. The government set up the National Aids Council and the National Aids Trust to collect and administers the AIDS levy, set at 3\% of salaries for formally employed people. Fifty per cent of the AIDS levy is reserved for medicines procurement, with the balance allocated to prevention, awareness and administration costs. 
The government issued a compulsory license to manufacture ARVs and promised to purchase $75 \%$ of the locally manufactured medicines (Osewe et al., 2008). It is important to recognize that the government could only issue a compulsory license because Zimbabwe had built the infrastructure and capabilities to locally manufacture pharmaceutical drugs from the 1950s (Chapter 1). Transferring the technology in order to manufacture ARVs locally was thus possible because of this industrial background.

However, in spite of government's intentions, the hyperinflationary environment of the 2000s constrained public health financing capacity, culminating in the collapse of the public health system (2003 to 2009). The result was a shift to high donor dependence for financing the public health system and medicines procurement. This shift incapacitated public procurement as an industrial policy tool (NECF, 2010), and was the greatest cause of decline in local industry capacity utilization. Reliance on donor funding that fragments public procurement policies continues to pose a demand-side constraint for local pharmaceutical manufacturing.

However, there are exceptions: one donor-funded programme in Zimbabwe provides an unusual example of support from donors for local pharmaceutical production. Ordinarily, in many African health settings, donor-funded health programmes tend to import medicines from India or China independently of public procurement mechanisms. For example, in Zimbabwe the principal purchaser of anti-retroviral drugs for The Global Fund is the United Nations Development Programme (UNDP), which procures the drugs through their pooled procurement base in Copenhagen. ${ }^{1}$ This removes public procurement as an industrial policy tool from the available policy arsenal for stimulating and supporting innovation and industrial development in the African context. In such situations, the market becomes unreachable for local manufacturers.

However in this case, purposive support for local manufacturing was provided. The Extended Support Programme funded by the European Union and DFID (the UK Department For International Development) supported local manufacturers CAPS Pharmaceuticals and Varichem in Zimbabwe to manufacture and supply medicines to the local health system during the era of economic collapse (Table 13.1). This example shows that donor-funded programmes can support local industry and operate as an effective industrial policy tool. Table 13.1 shows that CAPS and Varichem were contracted to supply more than US $\$ 4$ million worth of drugs to the programme. The contract value shows the values 
Table 13.1 Donor support for local industry through contracting for local health supplies: Zimbabwe

Contracts for drug supply by some pharmaceutical manufacturing firms and importers

\begin{tabular}{lrcc}
\hline Supplier & $\begin{array}{c}\text { Contract Value } \\
\text { (Euro) }\end{array}$ & $\begin{array}{c}\text { Value Delivered } \\
\text { (Euro) }\end{array}$ & $\begin{array}{c}\text { \% Completion } \\
\text { of Supply }\end{array}$ \\
\hline Varichem Lot 2 & $1,788,800$ & $1,522,404$ & 85.11 \\
Varichem Lot 4 & 198,500 & 198,500 & 100 \\
CAPS Lot 1 & $2,289,784$ & 961,139 & 41.98 \\
PCD Lot 2 & 433,967 & 433,967 & 100 \\
PCD Lot 3 & 570,235 & 570,235 & 100 \\
PCD Lot 4 & 198,500 & 198,500 & 100 \\
GHC & $1,585,464$ & $1,585,379$ & 99.99 \\
Mission Pharma Lot 1 & 986,615 & 981,044 & 99.44 \\
Mission Pharma Lot 2 & 63,000 & 63,000 & 100 \\
SJV & 253,280 & 253,280 & 100 \\
Total & $\mathbf{8 , 3 6 8 , 1 4 5}$ & $\mathbf{6 , 7 6 7 , 4 8 8}$ & $\mathbf{8 0 . 8 7}$ \\
\hline
\end{tabular}

Source: EU, 2010.

of medicines that were supposed to be delivered, and value delivered shows what the companies had actually delivered by the time the report was compiled (EU, 2010). Table 13.1 also shows that locally based pharmaceutical wholesalers, including PCD, GHC, Mission Pharma and SJV, were allocated quotas that they filled through imports.

A key issue raised by this example is the political scope for governments to incentivize or compel large donors to purchase locally manufactured pharmaceutical products. Such a move can increase governments' space for policy manoeuvre. The South African government, for example, insists on local suppliers in many circumstances: when foreign companies win tenders, they must go into an agency arrangement with a local South African firm, as exemplified by a case where a Zimbabwean firm won a tender to supply ARVs to the South African public health system and had to partner with a South African firm. Other African governments have been less energetic or effective in imposing local partner requirements on overseas suppliers.

\section{Public industrial procurement to serve health needs and values}

The previous section has centred on the scope for aligning demand for health commodities with industrial development needs. This section 
reverses the view, to ask: To what extent can medicines procurement be shaped to ensure that local industrial development increasingly serves the health needs of the populations dependent on the local health system? This is a question raised and addressed for the Brazilian healthindustrial complex and its policy development in Chapter 9. Here, we examine schemes that link reimbursement and assessment of a product's value to the impact that products have in real-world contexts. These efforts can be seen as reflecting a desire to link the introduction of new products to competent health care, which allow for maximum access and benefit. The objective is to bring local industrial production and innovation closer to the health needs it should serve

Our focus is on a particular innovative procurement mechanism: value-based pricing of medicines. While this is to date a mechanism largely experimented with in high-income countries, we think it is important because it shifts the attention of procurement policy from a market (often monopoly) price for an already developed drug to an assessment of how a drug will actually work in particular country contexts and for identified needs. Its attractiveness is in indicating ways forward in adapting procurement to a focus on population health benefit and patient needs.

The broader lessons are particularly pertinent for developing country contexts, where fragmented and marketized health systems may generate wide gaps between population needs and market demand. Public and donor procurement mechanism then need to specify as well as address population health needs. An early and widespread example of such an innovative procurement mechanism was the essential medicines lists, developed by the WHO and by health activists, that specify priorities for procurement of essential medicines, by generic names, to support access to drugs that are deemed essential for particular populations (Laing et al., 2003). The parallel to the discussion of VBP here is that the essential medicines lists also aimed to shift the design of public procurement towards better serving needs.

\section{Public procurement and industrial innovation for unmet need}

The use of VBP has focussed to date on the role it can play in relation to innovator drugs targeted for currently unmet or poorly met health needs. The dominant framework of thought on incentives for industrial innovation identifies an imbalance between investment risk in innovation and reward for the innovation. This 'market failure' is then put forward as the rationale for public sector investment in basic science: there is insufficient incentive for the private sector to invest in basic and 
long-term research, so the public sector should underpin drug discovery with support for early-stage research.

However, this conceptual apparatus does little to explain the actual way in which the public and private sectors invest in drug discovery, development and procurement. At all stages, public and private sectors inform each other in influencing the rate and direction of innovation. As argued in the introduction, markets and other institutions are co-created by public and private sectors. The discussion of VBP locates it as one example of this changing pattern of political and economic interaction and articulation, in this case in the way in which drugs are purchased and prices are determined.

One observation from recent patterns of public and private interaction is that market and institutional failures clearly occur not only at the research stage but also at the other end of value chain - at the market access end. This is especially the case in developing country contexts, and a growing international focus on policy, charitable and public sector initiatives has emerged over the past two decades using procurement to address the problems. The institutional vehicles include The Global Alliance for Vaccines and Immunization (GAVI), set up in 2000, which brings together public and private actors to address the challenge of equal access for new and underused vaccines programmes in the world's poorest countries. As of 2013, GAVI stakeholders have committed US $\$ 8.2$ billion to achieving their mission and have supported the immunization of an estimated 440 million children (GAVI, 2013).

The Global Fund and access initiatives that are disease specific include other examples of efforts to raise the financial endowment needed to generate innovation, product uptake and access to markets for producers, as well as access to medicines for the patients. Their procurement initiatives are designed to support the skills, finance and technological resource endowment required for innovation. In Europe, there has also been renewed policy thinking about how to construct public and private interaction so that appropriate products get to patients (Chataway et al., 2012). Initiatives such as the European Commission's Innovative Medicines Initiatives support basic and applied research (Morgan Jones et al., 2013).

Other high-income country initiatives such as the Innovate UK stem cell programme support policy thinking and address regulatory, business development, funding and access to market issues. At the same time, new approaches to health technology assessment constitute what has been colloquially termed 'the fourth hurdle'. Going beyond efficacy, effectiveness and product approval, they cover value assessments and relate 
to pricing and procurement. Procurement and the technology assessment that goes along with it should be seen as a form of regulation.

Previous work has suggested that well-targeted systems of regulation and standard setting result in better outcomes than broadbrush approaches in terms of overall outcomes, including innovation (Chataway et al., 2006). For instance, broad regulatory judgment across Europe that banned all products that left chemical residue in water had the unintended consequence of encouraging use of products that were environmentally damaging in a number of other respects than the products that had been banned. The message this regulation sent out to innovators who had worked on creating more environmentally friendly products was negative. It may well be the case similarly that regulation that bans all use of medicines that have undesirable consequences for a very limited number of patients can result in treatments that are less beneficial for the majority. New regulatory science as conceived of by the US Food and Drug Administration (FDA) and the European Medicines Agency (EMA) hopes to target regulation ever more carefully to those who are at risk.

\section{Value-based pricing}

This hope that targeted policy and intervention will deliver better results also underpins value-based pricing. The central idea of VBP is that the price of a drug may differ according to the impact that it has on different groups of patients, and maybe also across different health system contexts (Claxton et al., 2008). The desire to become more targeted and specific is common to both traditional rule-based regulation and innovative procurement-based regulation.

Lying behind VBP is a concept of health benefits and costs. Pricing of new innovator drugs is a question not of how much they cost, but of how much the firm can take out of a health system through the price it manages to charge. Where there is a highly competitive market for a medicine, competitive tendering can drive down prices. Where there is a monopoly supplier, the price is a matter for negotiation if procurement agencies have the competence and methodologies. A recent MSF report reported from contacts with nine pharmaceutical companies that value-based and differential pricing strategies were used predominantly in non-competitive markets for vaccines (e.g. for new products) where manufacturers do not have to compete on price (MSF, 2015).

Since resources in all health systems are limited, health economists use tools for technology assessment to feed into assessments of whether a certain therapy should be reimbursed. The concept of the incremental 
cost effectiveness ratio (ICER) has become one driver of reimbursement for new drugs. Along with measures of Quality Adjusted Life Years (QALYs), ICER calculations are used to measure health benefit and cost to health care provider, and these metrics are used to compare the attractiveness of different therapies. VBP provides a different approach to the logic of reimbursement. The UK is one of the countries that has been debating the introduction of a new way of determining the price for new drugs. The new UK regime has been partly driven by fiscal austerity in the country, in which funds for the purchase of new drugs may well depend on savings in other aspects of health spending. VBP seems to offer a broader approach to pricing decisions, which looks at the impact of drugs on overall health and social care systems.

The UK Department of Health has traditionally used a pharmaceutical price regulation scheme to control expenditure on branded drugs. ${ }^{2}$ Recently, however, it has been considering a move to a more outcomesor value-based approach (Persson et al., 2010). Like the calculations of quality-adjusted life years (QALYs) gained from using the new drug, VBP would also assess the benefits of a drug to individuals. The difference is that VBP signals a move to determining the price to be paid for the drug on the basis of assessment of a drug's impact in terms of health benefits and its contributions to the overall health system. The value-based price is in theory the price that ensures that health benefits for patients and the wider society exceed the health benefits displaced elsewhere in the health system and in the society due to the medicines' additional costs (Camps-Walsh et al., 2009; Claxton et al., 2008). The move is also to a more targeted and perhaps more adaptive system, with ongoing assessments of a drug's value potentially influencing its price. Again in theory, the calculation would take into account the importance of incentives for innovation.

The move has a number of implications, and Verhoef and Morris (2015) provide a summary of what value criteria other than QALYs (or similar measure of patient-level health gains) have been advanced in the literature as possible components of VBP. These include:

- Wider patient- or disease-related value criteria such as severity of disease (e.g. whether it is an acute, chronic, rare or terminal disease); unmet need; size of relevant population; age groups particularly suffering an impact of the disease (e.g. children); socially disadvantaged patients; number of other treatment options.

- Health care-related value criteria: being treated at a convenient time and location and after only a short wait; being treated in a way that 
patients consider less unpleasant (e.g. taking a medicine once a week as opposed to three times a day); and the degree of risk of the treatment.

- Wider societal value criteria such as ability of patients (and carers) to resume work or to work more productively; cost savings to other publicly funded services (e.g. social care), patients or carers; and how innovative the medicine is.

Some versions of VBP schemes might also involve differential pricing for different patient cohorts. For example, a group of patients with one genetic makeup may benefit more than another group, and therefore the price paid for the drug being taken by the group that benefits more would be higher.

Value attributes will need to be collected, measured, aggregated and converted to evaluate a 'value metric' (Deloitte, 2012). ${ }^{3}$ The data that will feed into this assessment will need to go beyond purely clinical trial data. Real-world data - that is, data relevant to the drug in use, not just in trials - would apply both before the market launch (e.g. up-to-date cost of illness data) and post-launch: comparative real-world data, information on side effects and changes in effectiveness over time (Greiner, 2011). The sources of such data could transcend patients, clinicians, hospitals and social networks. The quality of the data and its format, governance and ethical considerations are likely to influence the feasibility and extent to which VBP can reflect real-world values. There may well be a need for the development of new methods which can assess value in different contexts and under different conditions, and which can incorporate trade-offs.

A move towards VBP is certainly not without its complexities and dangers, and it is important to note that only a limited number of countries have attempted to implement VBP schemes. However, it is also the case that those countries do appear to be experiencing benefits as a result of the schemes they have implemented. Sweden is the most widely cited example of a country that has implemented a workable and successful scheme. Evidence from Sweden summarized in Persson (2012) suggests that a VBP scheme may be well placed to encourage the adoption of innovative medicines, especially those that address unmet needs. This is particularly important in the case of orphan drugs designed to treat rare diseases and which due to their high cost-per-QALY often fail to obtain reimbursement. The Swedish Dental and Pharmaceutical Benefits Agency (TLV), from June 2003 to April 2010, received 30 requests for orphan drugs reimbursements and awarded 29 (Cochrane et al., 2015). 
Nevertheless, there is limited evidence about how the approach can work in practice, and the evidence available comes from international examples applying only a few elements of the VBP approach. The situation is made additionally complex because VBP metrics are often used on conjunction with other schemes. Sweden combines VBP with other approaches such as coverage with evidence development (CED) schemes (Cochrane et al., 2015), and this in turn makes gathering evidence on the effectiveness of VBP approaches challenging (Persson, 2012).

Additionally, it is difficult to judge what impact funder silos, which mean that costs and benefits from health and social care, for example, are calculated without reference to each other, will have on the way that treatments are rewarded. How will methodologies be developed to assess the full costs and benefits in the health, social care and domestic settings? Can multiple budgets be brought together and analysed coherently? These and other unresolved issues seem to have led to delays in the introduction of VBP-based schemes, although thinking about how VBP might be introduced on a large scale is beginning to influence approaches to determining price.

So why focus on VBP? Earlier we argued that the classic image of publicly supported fundamental science and private support for more applied work is not useful. Innovation emerges from a more diverse and complicated patterns of interactions between private and public sectors that work across the $\mathrm{R} \& \mathrm{D}$ and product development processes to create new medicines and make them accessible to patients. The public sector has to intervene in multiple ways to ensure that incentives offered for drug development are balanced with broad public interest agendas in ensuring access to medicines in response to need.

Value-based pricing is thus not about the drug; it is about the impact of the drug in the context of the health system and unmet health needs. In this respect, VBP could act as an incentive for innovation that is more focussed on delivery of and access to products that are designed to meet the most pressing needs in particular contexts. Perhaps VBP could be thought alongside other mechanisms to try and address local health needs in developing countries. For example, it could be used in conjunction with product development partnerships (PDP) or market guarantees focussed on particular health challenges.

A shift to pricing mechanisms for procurement that use local health needs assessment is challenging for developing countries. Nguyen et al. (2014) emphasize the difficulties more broadly with pharmaco-economic evaluation in developing countries, citing a lack of capacity due to a shortage of qualified researchers and health care data. Fragmented 
health systems generate poor data on health needs. However, African and other low- and middle-income public procurement bodies face the challenge of procuring innovator medicines as well as generics, and need to develop assessment skills for price negotiations. More generally, a procurement process that seeks to identify population health needs and then encourage local supply development has to build up tools over time to assess the benefits of local innovations.

\section{Conclusion: procurement as development policy and process}

Public procurement is an important development tool, and in medicines it needs to be designed to interlock industrial innovation and development with the huge scale of African unmet health need. Given the scale of medicines procurement, and its life-or-death importance, its institutional design and operation therefore require much more policy and research attention. Medicines procurement is at the same time highly technical - requiring capabilities identified in this chapter in financing and health benefit assessment - and also highly political. It involves sets of rules, but it is also a complex set of social and institutional relationships. When it goes wrong, both health and industry suffers.

We have suggested two innovative aspects of procurement that will occupy much more attention of African policy makers. The first is the procurement payment systems and the ways in which they can be designed to act as assets and incentives for local industrial development. The other is the assessment processes that can underpin pricing systems that go beyond competitive tendering to generate negotiated prices for innovative suppliers. Finally, we have argued that value-based pricing is just one example of potential innovative procurement mechanisms that can be designed to have at their heart the objective of both incentivizing industrial suppliers and directing their efforts to address unmet health need. Public procurement may be underfunded by national budgets, but collaboration with donors and private firms can, if purposively designed, promote local production, innovation and access to medicines.

\section{Notes}

The authors would like to thank Sonja Marjanovic from RAND Europe for helpful conversations about this chapter.

1. The Global Fund to Fight AIDS, Tuberculosis and Malaria, http://www.theglobalfund.org/en/ (accessed 25 April 2015). 
2. The NHS spends about $£ 11$ billion annually on drugs of which $£ 8$ billion is on branded drugs. This represents about $13 \%$ and $10 \%$ of available resources, respectively (Claxton et al., 2008).

3. Figure 6 in this report has some case vignettes of VBP agreements.

(c) (7) Except where otherwise noted, this work is licensed under a a copy of this license, visit https://creativecommons.org/version4 